${ }^{3}$ MR Medicina Reumatológica, Rheumatology, GHP, Argentina; ${ }^{4}$ Hospital Posadas, Rheumatology, El Palomar, Argentina; ${ }^{5}$ Instituto Medico Humanitas, Rheumatology, Resistencia, Argentina; ${ }^{6}$ Private Practice, Rheumatology, Ciudad Autonoma de Buenos Aires, Argentina; ${ }^{7}$ Hospital Madariaga, Rheumatology, Posadas, Argentina; ${ }^{8}$ Private Practice, Rheumatology, Buenos Aires, Argentina; ${ }^{9}$ Hospital El Cruce - Nestor Kirchner, Rheumatology, Florencio Varela, Argentina; ${ }^{10}$ Clinical Research Institute Quilmes, Rheumatology, Quilmes, Argentina;

${ }^{11}$ Hospital De Quilmes, Rheumatology, Quilmes, Argentina

Background: Tofacitinib (TOF), an oral JAK inhibitor, is approved for the treatment of rheumatoid arthritis (RA) either as monotherapy or in combination with background methotrexate (MTX). Despite the current evidence of efficacy from randomized controlled trials and open-label long-term extension studies, evidence of effectiveness and safety in real-world settings is limited, not only in Argentina but also in Latin America.

Objectives: To describe effectiveness, safety and persistence of TOF therapy in RA patients from public and private medical centers from Argentina. In addition, establish prognostic factors for clinical remission at 3 months and TOF monotherapy at 12 months.

Methods: A retrospective, observational and multicentre study was performed from an analysis of medical records of 10 medical centers. RA patients (ACR/ EULAR, 2010) and age $\geq 18$ years who had received or are under treatment with TOF until June 2020 were included. The data collection was done on a standard database that included baseline data and at 3, 6 and 12 months. Clinical remission was defined as DAS28-ESR $<2,6$. Adverse events, treatment duration, TOF treatment persistence at last visit and discontinuation cause were assessed. Comparison to baseline values was performed using Wilcoxon sign for numerical variables and McNemar's test for categorical variables. Treatment persistence was analyzed using Kaplan Meier's technique. Multivariate analysis was performed using R software and its library packages (Lme4, Tidyverse and ggpubr). A $p$ value $<0.05$ was considered significant.

Results: A total of 167 patients were included (78.4\% were female). At baseline, the median age was 53 years (IQR 43-63 years), median disease duration was 4 years (IQR $2-13$ years). RF was positive in $85.6 \%$ of patients, ACPA in $80.8 \%$ and structural radiological damage was present in $71.8 \%$. Previous use of MTX was $97 \%$, leflunomide $74.8 \%$ and biologic therapy $42.5 \%$ (28.74\% 1 biologic, $11.98 \% 2$ biologics and $1.8 \% \geq 3$ biologics). TOF dose: $48 \% 11 \mathrm{mg} /$ day and $52 \%$ $5 \mathrm{mg} \mathrm{BID}$. A statistically significant difference was observed not only in disease activity $(p<0.0001)$ but also in the requirement of MTX and PDN $(p<0.0001)$ in the 12 months evaluated. Remission significantly increased from baseline to month 3 and to a much lesser extent to month $6(p<0.001)$. The mean duration of treatment with TOF was $20.10 \pm 15.25$ months. Treatment persistence was $93.84 \%$ at 3 months and $91.24 \%$ at 6 months. In those patient who achieved REM at month 3 , a statistically significant differences in duration of RA ( $p$ 0.0002), structural radiological damage ( $\mathrm{p} 0.011)$, basal disease activity $(\mathrm{p} \mathrm{0.018})$ and prior treatment with biological therapy ( $p$ 0.017) was found when compared with patients who remained active. Furthermore, in univariate logistic regression analysis, 5 years or more of disease duration was associated with a 3 times higher risk of not achieving clinical remission at 3 months (odds ratio $=0.35,95 \% \mathrm{Cl}=0.15$ 0.83 ). In the multivariate logistic regression analysis, previous biological therapy was the only predictor associated with a decrease in the probability of clinical remission $(p<0.008)$. Adverse events were registered in 26 patients (herpes zoster, $n=9$ ).
Conclusion: The effectiveness of TOF was observed not only in the clinical response achieved but also in the dose titration or withdrawal of MTX and PDN. The safety profile did not show any difference from long-term extension studies. At 12 months, $86.81 \%$ of the patients persisted with TOF therapy. We found prognostic factors associated with clinical remission at 3 months but those associated with monotherapy at 12 months could not be defined due to small number of patients analyzed that could have generated lack of statistical power, although more studies are required to confirm these assumptions.

Disclosure of Interests: Maria Del Rosario Maliandi: None declared, Yanina Silvia Malvano: None declared, Alejandra Cusa: None declared, María Julieta Gamba: None declared, Ramiro Gomez Speakers bureau: Abbvie, Novartis, Julio Got: None declared, Oscar Gut: None declared, Ursula Vanesa Paris: None declared, Maria Andrea Spinetto: None declared, Carolina Mariach None declared, Alejandra Ines Abalo: None declared, Adrián Estevez Speakers bureau: Bristol-Meyer-Squibb, Jose Luis Velazco Zamora: None declared, Juan Pablo Vinicki: None declared

DOI: 10.1136/annrheumdis-2021-eular.1645

\section{POS0668 REAL WORLD EFFECTIVENESS OF BARICITINIB IN THE SWISS RHEUMATOID ARTHRITIS REGISTER (SCQM-RA)}

B. Gilbert ${ }^{1}$, D. Courvoisier ${ }^{1}$, D. Mongin ${ }^{1}$, K. Lauper ${ }^{1,2}$, C. Perrier ${ }^{3}$, R. Muller ${ }^{4}$ A. Finckh ${ }^{1}{ }^{1}$ Geneva University Hospitals, Division of Rheumatology, Geneva, Switzerland; ' ${ }^{2}$ University of Manchester, Centre for Musculoskeletal Research, Manchester, United Kingdom; ${ }^{3}$ Eli Lilly SA (Suisse), Medical Department, Vernier, Switzerland; ${ }^{4}$ Kantonsspital Aarau, Medical University Department, Aarau, Switzerland

Background: When not responding to conventional synthetic DMARDs (csDMARDs), rheumatoid arthritis (RA) patients may receive biological DMARDs (bDMARDs) or targeted synthetic DMARDs (tsDMARDs) including baricitinib (BARI). While BARI has demonstrated efficacy in randomized controlled trials, limited studies have established comparative effectiveness in real world settings, in particular when used in b/tsDMARD-naïve patients.

Objectives: To analyze the effectiveness of BARI versus alternative bDMARDs, as assessed by drug maintenance over time and by response rates at 12 months.

Methods: This is a nested study of RA patients, within the prospective Swiss Clinical Quality Management (SCQM) observational cohort.

All treatment courses (TC) with BARI or alternative bDMARDs initiated between 2017-09-01 and 2020-06-01, with at least one follow-up visit, were included. TC with BARI were compared to TC with alternative bDMARDs (non-BARI), including all b/tsDMARDs except rituximab. The non-BARI group was then subdivided into TNF inhibitors (TNFi) and other mode of action bDMARDs (OMA), excluding tsDMARDs. A secondary analysis focusing specifically on b/tsDMARD naïve patients was conducted.

Baseline characteristics were compared using ANOVA or $\alpha 2$ tests. A Cox-model survival analysis assessed drug maintenance. 12-month response rates were estimated using an attrition-corrected, confounder-adjusted approach (1). CDA score $\leq 10$ defined low disease activity state (LDA), and CDAl score $\leq 2.8$ defined remission.

Table 1. Baseline characteristics of studied population

\begin{tabular}{|c|c|c|c|c|c|c|c|c|c|c|}
\hline \multirow[t]{3}{*}{ Variable } & \multicolumn{3}{|c|}{$\begin{array}{l}\text { Overall comparison: } \\
\text { BARI vs non-BARI }\end{array}$} & \multicolumn{3}{|c|}{$\begin{array}{c}\text { Subgroup analysis 1: } \\
\text { by bDMARD type (tsDMARD excluded) }\end{array}$} & \multicolumn{4}{|c|}{$\begin{array}{c}\text { Subgroup analysis 2: } \\
\text { In b/tsDMARD-naïve patients }\end{array}$} \\
\hline & $\begin{array}{c}\text { BARI } \\
\text { (TC = 273; } 273 \\
\text { patients) }\end{array}$ & $\begin{array}{c}\text { Non-BARI } \\
\text { (altogether) } \\
\text { (TC = 945; } 755 \\
\text { patients) }\end{array}$ & $p$ values & $\begin{array}{c}\text { TNFi } \\
\begin{array}{c}\text { (TC }=473 ; 408 \\
\text { patients })\end{array}\end{array}$ & $\begin{array}{c}\text { OMA } \\
\text { (TC = 318; } 298 \\
\text { patients) }\end{array}$ & $\begin{array}{l}\text { p values } \\
\text { (vs BARI) }\end{array}$ & $\begin{array}{c}\text { BARI } \\
(n=46)\end{array}$ & $\begin{array}{c}\text { TNFi } \\
(n=225)\end{array}$ & $\begin{array}{c}\text { OMA } \\
(n=65)\end{array}$ & $p$ values \\
\hline & \multicolumn{2}{|c|}{$\begin{array}{c}\text { Mean (SD) } \\
\text { Otherwise: } n \%\end{array}$} & & \multicolumn{2}{|c|}{$\begin{array}{c}\text { Mean (SD) } \\
\text { Otherwise: n \% }\end{array}$} & & \multicolumn{3}{|c|}{$\begin{array}{c}\text { Mean (SD) } \\
\text { Otherwise: n \% }\end{array}$} & \\
\hline Concomitant csDMARD & $41 \%$ & $46 \%$ & 0.17 & $54 \%$ & $41 \%$ & $<0.01$ & $50 \%$ & $61 \%$ & $48 \%$ & 0.1 \\
\hline Line of Therapy & $17 \%$ & $35 \%$ & $<0.01$ & $48 \%$ & $20 \%$ & $<0.01$ & $100 \%$ & $100 \%$ & $100 \%$ & \\
\hline \multicolumn{11}{|l|}{$-1^{\text {st }}$ (= bio-naive) } \\
\hline$-2^{\text {nd }}$ & $20 \%$ & $23 \%$ & & $23 \%$ & $23 \%$ & & & & & \\
\hline$-3^{\text {rd }}$ & $19 \%$ & $16 \%$ & & $11 \%$ & $24 \%$ & & & & & \\
\hline$-4^{\text {th }}$ or later & $44 \%$ & $26 \%$ & & $18 \%$ & $33 \%$ & & & & & \\
\hline Female & $78 \%$ & $74 \%$ & $<0.21$ & $74 \%$ & $73 \%$ & 0.28 & $70 \%$ & $71 \%$ & $74 \%$ & 0.88 \\
\hline Age & $59(14)$ & $56(14)$ & 0.01 & $52(15)$ & $58(13)$ & $<0.01$ & $57(15)$ & $51(14)$ & $57(16)$ & $<0.01$ \\
\hline Disease duration (years) & $13(10)$ & $10(9)$ & $<0.01$ & $8(9)$ & $11(9)$ & $<0.01$ & $5.5(6.45)$ & $5(7)$ & $6.5(9)$ & 0.243 \\
\hline CDAI baseline & $15(9)$ & $15(10)$ & 0.9 & $14(9)$ & $16(11)$ & 0.05 & $13(7)$ & $14(9)$ & $14(10)$ & 0.72 \\
\hline Previous tsDMARD (non-BARI) & $33 \%$ & $8 \%$ & $<0.01$ & $4 \%$ & $11 \%$ & $<0.01$ & $0 \%$ & $0 \%$ & $0 \%$ & \\
\hline TC duration > 12-months & $37 \%$ & $29 \%$ & 0.01 & $27 \%$ & $30 \%$ & 0.02 & $37 \%$ & $29 \%$ & $34 \%$ & 0.52 \\
\hline
\end{tabular}


Results: Overall, 1218 eligible TC (from 1028 patients) were initiated during the study period (273 in BARI, 154 other tsDMARD, 473 in TNFi and 318 in OMA). Drug maintenance was significantly shorter for TNFi compared to BARI, even after adjustment for potential confounders (Hazard ratio (HR) for drug discontinuation 1.85 (95\% Cl [1,40 - 2,43]); $\mathrm{p}<0.001)$. Drug maintenance was also numerically shorter for the OMA group compared to BARI, but the difference was not significant (HR 1.18 (95\% Cl [0.87-1.60]); $p=0.28$ ). These differences were larger when analysing only bDMARD-naïve patients (Figure 1a).

All TC taken together, the rates of LDA and remission did not differ significantly between the 3 groups at 12 months. LDA ranged from $63 \%$ to $67 \%$ (BARI vs OMA $p=0.87$; BARI vs TNFi $p=0.81$ ) and remission from $19 \%$ to $23 \%(B A R I$ vs OMA $p=0.30 ;$ BARI vs TNFi $p=0.77$; Figure $1 b$ ).

Conclusion: BARI demonstrated a significantly higher overall drug maintenance than TNFi, and a similar drug maintenance to OMA, both in a bDMARD-naïve population and in the overall population. The adjusted 12-month response rates did not differ between BARI, TNFi and OMA groups. These results suggest that prescription of BARI after csDMARD has at least similar outcomes as alternative bDMARDs.

REFERENCES:

[1] Lauper, K., et al. Sat0588. Annals of the Rheumatic Diseases 78 (2019).

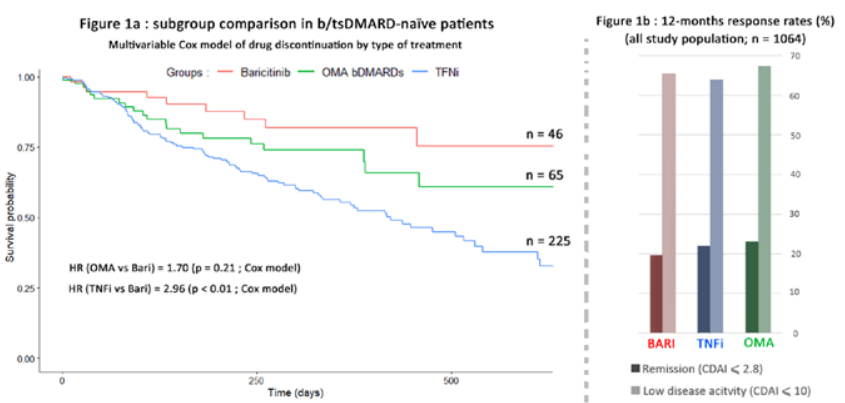

Disclosure of Interests: Benoit GILBERT: None declared, Delphine Courvoisier: None declared, Denis Mongin: None declared, Kim Lauper Consultant of: Gilead Galapagos, Grant/research support from: AbbVie, Clementine Perrier Shareholder of: Eli Lilly, Employee of: Eli Lilly, Rudiger Muller Consultant of: AbbVie, Novartis, Grant/research support from: GEBRO Pharma, Axel Finckh Speakers bureau: AbbVie, BMS, Pfizer, Eli-Lilly, Consultant of: AbbVie, BMS, Pfizer, Eli-Lilly, Grant/research support from: BMS, Pfizer, Eli-Lilly

DOI: 10.1136/annrheumdis-2021-eular.1781

\section{\begin{tabular}{|l|l}
\hline POS0669 HYPOGLYCAEMIA FOLLOWING JAK INHIBITOR \\
\hline
\end{tabular} TREATMENT IN DIABETES MELLITUS PATIENTS WITH RHEUMATOID ARTHRITIS}

J. van Lint $^{1}$, F. Van Hunsel ${ }^{1}$, S. Tas ${ }^{2}$, M. Nurmohamed ${ }^{3}$, H. Vonkeman ${ }^{4,5}$, R. Hebing ${ }^{3}$, F. Hoentjen ${ }^{6}$, M. van Doorn', B. van den Bemt ${ }^{8,9}$, E. van Puijenbroek ${ }^{1,10}$, N. Jessurun ${ }^{1} .{ }^{1}$ Netherlands Pharmacovigilance Centre Lareb, 's Hertogenbosch, Netherlands; ${ }^{2}$ Amsterdam UMC, Rheumatology \& Clinical Immunology, Amsterdam, Netherlands; ${ }^{3}$ Amsterdam Rheumatology and Immunology Center, location Reade, Rheumatology, Amsterdam, Netherlands; ${ }^{4}$ Medisch Spectrum Twente, Rheumatology, Enschede, Netherlands;

${ }^{5}$ University of Twente, Psychology, Health \& Technology, Enschede, Netherlands; ${ }^{6}$ RadboudUMC, Gastroenterology, Nijmegen, Netherlands; ${ }^{7}$ Erasmus MC, Dermatology, Rotterdam, Netherlands; ${ }^{8}$ Sint Maartenskliniek, Pharmacy, Nijmegen, Netherlands; ${ }^{9}$ RadboudUMC, Pharmacy, Nijmegen, Netherlands; ${ }^{10}$ University of Groningen, Groningen Research Institute of Pharmacy, Pharmacotherapy, Epidemiology \& Economics, Groningen, Netherlands

Background: Janus kinase (JAK) inhibitors are effective small molecular drugs for rheumatoid arthritis (RA) and other immune mediated inflammatory diseases (IMIDs). JAK inhibitors exert their immunosuppressive effects by suppressing the action of JAK, an intracellular tyrosine. Although infections are the most reported side effects, potential glucose lowering effects in patients with diabetes mellitus (DM) have been described in literature and have also been reported as suspected adverse drug reactions (ADRs) to the National Pharmacovigilance Centre Lareb in the Netherlands (1).

Objectives: To assess and describe suspected adverse effects of JAK inhibitors on glucose levels in diabetic patients with rheumatic diseases and other IMIDs, as reported in daily practice.
Methods: We describe ADR reports of tofacitinib and baricitinib in the European pharmacovigilance Eudravigiliance (EV) database from initiation to 12 January 2021. All ADRs in EV are coded according to the Medical Dictionary for Regulatory Activities (MedDRA). We included all reports indicating hypoglycaemia in patients with reported DM type 1 and 2 or with antidiabetic drugs as concomitant medication. This could include oral antidiabetics as well as insulins.

Results: On 12 January 2021 the EV database included 32 ADR reports, concerning 32 diabetic patients, indicating hypoglycaemia associated with the use of JAK inhibitors (15 tofacitinib, 17 baricitinib), out of 32,484 ADR reports in total concerning tofacitinib or baricitinb (Table 1). Most patients (25 patients, $78 \%$ ) used the JAK inhibitor for rheumatoid arthritis. The suspected ADR with MedDRA Preferred Term 'Hypoglycaemia' was reported for 16 patients and MedDRA Preferred Term 'Decreased blood glucose' was reported for 15 patients. In one case increased insulin sensitivity was described as suspected ADR of baricitinib. In this case, the insulin dose had to be reduced to prevent hypoglycaemia. Of note the insulin dose had to be increased after temporary discontinuation of baricitinib and was reduced again after baricitinib was restarted. Additionally, in six cases improvements of glycaemic control were described after discontinuation or dose reduction of the JAK inhibitor or antidiabetic drug. Improvements were also described after unknown action or unchanged treatment with JAK inhibito in eight cases.

Conclusion: JAK inhibitors may induce hypoglycaemia by increasing insulin sensitivity, and consequently may reduce the need for antidiabetic medication (2-3). Healthcare professionals should be alert for these potential ADRs when starting a JAK inhibitor in patients with DM as comorbidity. More research is needed to support our findings and elucidate the underlying pharmacological mechanisms of this potentially beneficial effect of JAK inhibitors.

Table 1. Suspected adverse drug reaction reports indicating hypoglycaemia in diabetic patients using tofacitinib or baricitinib in the Eudravigilance database

\begin{tabular}{lcc}
\hline & Tofacitinib N (\%) & Baricitinib N (\%) \\
\hline No. of reports & $15(100)$ & $17(100)$ \\
Mean age years (range) & $65(56-78)$ & $62.2(48-78)$ \\
Female gender & $13(87)$ & $13(76)$ \\
Indication for JAK inhibitor & $11(73)$ & $14(82)$ \\
$\quad$ Rheumatoid arthritis & $3(20)$ & $3(18)$ \\
$\quad$ Unknown & $1(7)$ & \\
$\quad$ Arthritis & $6(40)$ & $11(65)^{\mathrm{a}}$ \\
Reported adverse drug reaction & $9(60)$ & $6(35)^{\mathrm{a}}$ \\
$\quad$ Hypoglycaemia & $6(40)$ & $3(18)$ \\
$\quad$ Decreased blood glucose & $2(13)$ & $2(12)$ \\
Time to onset after start JAK inhibitor & $1(7)$ & $1(6)^{\mathrm{b}}$ \\
$\quad$ Within 1 month & $3(20)^{\mathrm{c}}$ & $1(6)^{\mathrm{e}}$ \\
2-6months & $1(7)^{\mathrm{f}}$ & \\
$\quad$ More than 6 months & & \\
Improvement after action: & & \\
$\quad$ Drug withdrawal & &
\end{tabular}

a.In one case of baricitinib hypoglycaemia as well as decreased blood glucose were reported as adverse drug reactions.

b. Time to onset was unknown in 6 reports of tofacitinib and 12 reports of baricitinib

c. Tofacitinib withdrawal: 1 , sitagliptin withdrawal: 1 , tofacitinib and insulin withdrawal: 1

d.Baricitinib withdrawal: 1

e.Baricitinib: after insulin dose adjustments: 1

f.After tofacitinib withdrawal and insulin dose adjustments

\section{REFERENCES:}

[1] Fujita Y, et al. Case Rep Rheumatol. 2019.

[2] Bako HY, et al. Life Sci. 2019.

[3] Chaimowitz NS, et al. N Engl J Med. 2020.

Disclosure of Interests: Jette van Lint: None declared, Florence van Hunsel: None declared, Sander Tas Consultant of: Gebro, GSK, AbbVie, Galvani, Arthrogen, Galapagos, Grant/research support from: Pfizer, GSK, Celgene, BMS, Sanofi, AstraZeneca, Michael Nurmohamed Speakers bureau: speaker's fees from AbbVie, Bristol-Myers Squibb, Eli Lilly, Roche, and Sanofi, Consultant of consulting fees from AbbVie, Celgene, Celltrion, Eli Lilly, Janssen, and Sanofi, Grant/research support from: research funding from AbbVie, Bristol-Myers Squibb, Celgene, Eli Lilly, Janssen, MSD, Mundipharma, Novartis, Pfizer, Roche and Sanofi, Harald Vonkeman Grant/research support from: AbbVie, Amgen, AstraZeneca, BMS, Celgene, Celltrion, Galapagos, Gilead, GSK, Janssen-Cilag, Lilly, MSD, Novartis, Pfizer, Roche, Sanofi-Genzyme, all outside the submitted work., Renske Hebing: None declared, Frank Hoentjen Speakers bureau: served on advisory boards or as speaker for Abbvie, Janssen-Cilag, MSD, Takeda, Celltrion, Teva, Sandoz and Dr Falk, Consultant of: Celgene, Janssen-Cilag, Grant/ 